\title{
Effects of umbilical cord millking compared to differed cord clamping in term infants, a randomized controlled trial
}

Piyadigama I a, Devasurendra $\mathrm{LC}^{\mathrm{b}}$, Dissanayake $\mathrm{AD}^{\mathrm{c}}$, Gunawardana $\mathrm{K}^{\mathrm{d}}$

\section{Abstract}

Introduction: Differed cord clamping (DCC) at delivery is currently recommended to increase neonatal haemoglobin levels $(\mathrm{Hb})$ and reduce the risk of infant anemia. It needs waiting for two to three minutes, which is considered to be associated with most of its unwanted effects. An alternative could be umbilical cord milking (UCM) with early clamping. Although effects of UCM have been assessed in preterm neonates such evidence is sparse for term neonates.

Objectives: To evaluate whether the effects on $\mathrm{Hb}$, bilirubin and haemodynamic parameters in infants, and blood loss in the mother are better with UCM than with DCC during elective caesarean delivery at term.

Methods: Sixty term pregnant mothers undergoing elective caesarean delivery (CD) in Teaching Hospital Kandy, from $1^{\text {st }}$ February to $31^{\text {st }}$ March 2015 were randomized to UCM and DCC. The UCM group had the umbilical cord milked towards the umbilicus of the baby in a standard method soon after delivery. The DCC group had the umbilical cord clamped after two minutes of delivery or once the cord pulsations had ceased. Neonatal $\mathrm{Hb}$, bilirubin and haemodynamic parameters, and maternal blood loss were assessed within 48 hours of delivery.

Results: Thirty three participants underwent UCM while 27 participants underwent DCC. Main indications for the CD were past CD (47\%), failed induction (12\%), past bad obstetric history $(10 \%)$, maternal medical conditions $(8 \%)$ and suspected gross cephalo pelvic disproportion (8\%). All CD were performed under spinal aneasthesia.

There were no significant differences between the UCM and DCC groups with regard to mean neonatal $\mathrm{Hb}(17.6 \mathrm{~g} / \mathrm{dl}$, sd 2.0 vs $17.4 \mathrm{~g} / \mathrm{dl}$, sd $2.4, \mathrm{p}=0.67)$, mean neonatal total bilirubin $(111.8 \mathrm{mmol} / \mathrm{l}$, sd $47.6 \mathrm{vs} 123.0 \mathrm{mmol} / 1$, sd $35.0, \mathrm{p}=0.69)$ and mean maternal decrease in $\mathrm{Hb}(1.0 \mathrm{~g} / \mathrm{dl}$, sd 0.7 vs $1.3 \mathrm{~g} / \mathrm{dl}$, sd $1.0, \mathrm{p}=0.37)$. All the neonates had birth APGAR of 10 at 5 minutes. The volume of blood remaining in the placenta was significantly higher in the UCM group $(29.5 \mathrm{ml}$, sd $20.3 \mathrm{vs} 19.5 \mathrm{ml}$, sd 13.1, $\mathrm{p}=0.03)$.

Conclusions: Neonatal and maternal outcomes are not better with UCM than with DCC during elective CD.

Key words : Umbilical cord milking, Delayed cord clamping, Term, Haemoglobin, Bilirubin, Blood loss, Caesarean

a Senior registrar in Obstetrics and Gynaecology, University Obstetrics Unit, Colombo South Teaching Hospital, Colombo, Sri Lanka.

${ }^{b}$ Medical officer, Colombo South Teaching Hospital, Colombo, Sri Lanka.

c Senior registrar in Obstetrics and Gynaecology, Sri Jayewardenepura Hospital, Colombo, Sri Lanka.

${ }^{d}$ Professor and chair, Department of Obstetrics and Gynaecology, University of Peradeniya, Sri Lanka

Correspondence: Dr. Indunil Piyadigama MBBS MD

Email - indu_doc@hotmail.com

(D) https://orcid.org/0000-0002-3929-1330

Competing interests: The authors report no conflict of interest

\section{INTRODUCTION}

Anaemia in children is a common problem in Sri Lanka. According to the National Demographic and Health Survey 20067 the prevalence of anaemia among children under five years was $32.6 \%{ }^{1}$. The main contributor for childhood anaemia is iron deficiency. Iron deficiency can be detrimental to the development of neonates further progressing to childhood. Improving haemoglobin $(\mathrm{Hb})$ by $1 \mathrm{~g} / \mathrm{dl}$ will lead to a significant reduction in perinatal mortality and mental retardation ${ }^{2}$.

The amount of blood in the feto-placental circulation of a term neonate is estimated to be $120 \mathrm{ml} / \mathrm{kg}$. At the time of delivery with early cord clamping (ECC) this amount is distributed in a ratio of $2: 1$ to the fetus and the placenta respectively. Therefore with ECC $78 \mathrm{ml} / \mathrm{kg}$ of blood is estimated to be in the newborn circulation. Alternatively with deferred cord clamping (DCC) where clamping of the cord is differed approximately for about three minutes this distribution will be more towards the fetus in a ratio of about 7:1. DCC for three minutes will result in mounting of the blood in the fetal circulation up to $105 \mathrm{ml} /$ $\mathrm{kg}^{3,4}$.

The value of DCC against ECC had been studied by several randomized control trials (RCT) and meta-analyses over the years. The conclusion drawn from these studies is that there is a significant increase in haematocrit (HCT) as well as $\mathrm{Hb}$ in early neonatal life with DCC compared to ECC. Although this beneficial effect was not apparent in $\mathrm{Hb}$ by four months of age, the infants with DCC had higher iron stores reflected by higher serum ferritin levels at four months of age ${ }^{5,6}$. Therefore it was concluded that DCC was a low cost intervention for preventing neonatal and infant anaemia?

As DCC needs waiting for additional 2-3 minutes this can delay resuscitation of a newborn. Therefore it would be 
contraindicated in a very preterm neonate requiring ventilator support when a delay of even 30-40 seconds would be detrimental ${ }^{8,9}$. Other risks of DCC are transient tachypnea ${ }^{10}$, symptomatic polycythaemia ${ }^{11}$, increased blood viscosity $^{12}$ and hyperbilirubinaemia ${ }^{13}$ of the term infant. However no clinically significant adverse effects consequent to these changes have been demonstrated by well-designed studies.

Earlier descriptions of active management of third stage of labour (AMTSL) describes the administration of prophylactic uterotonics, clamping the umbilical cord within 60 seconds following birth of the infant and controlled cord traction ${ }^{14}$. From 2007 the WHO has recommended DCC as an integral component of AMTSL ${ }^{15}$ and DCC continue to be strongly recommended during all births including caesarean deliveries $(\mathrm{CD})^{16}$

It is difficult to describe which individual component of AMTSL reduces the risk of PPH and may be the full package contributes $^{6}$. One of the aims of AMTSL is to reduce the length of the third stage because the longer the placenta remains undelivered, the greater is the likelihood of maternal bleeding ${ }^{17}$. Although ECC is associated with a reduction in the length of the third stage of labour, DCC would be appropriate in all deliveries where there is no increased risk of PPH or the requirement of immediate ventilator support for the neonate ${ }^{16}$

The umbilical cord of a full term human neonate averages 50 to $70 \mathrm{~cm}$ in length and $2 \mathrm{~cm}$ in diameter ${ }^{18}$. It is estimated to contain on average $108 \mathrm{ml}$ of blood. This is about one third of the blood volume in a term infant, which approximates to about $300 \mathrm{ml}^{19}$. The umbilical cord is easily accessible to the operator and if this $100 \mathrm{ml}$ of blood can be forced in to the fetus this will invariably improve the fetal circulation with minimal delay. The act can mitigate the maternal and fetal effects of 2-3 minutes delay without hampering the fetal circulation.

There are several studies investigating the effect of UCM on preterm infants. These studies have concluded that in preterm infants UCM significantly increase the immediate $\mathrm{Hb}$ as well as the iron stores compared to $\mathrm{ECC}^{20,21}$. Also comparable outcomes with regards to the early $\mathrm{Hb}$ in the newborn is seen with UCM compared to $\mathrm{DCC}^{22}$. However there are concerns that forcing the blood by milking could traumatize red blood cells, which could lead to excess serum bilirubin (SB) in the fetus.

Unfortunately there are no published studies comparing UCM with DCC in term neonates. The objective of this research is to study whether UCM is better than DCC in improving $\mathrm{Hb}$ in term neonates.

\section{METHODS}

A parallel group, superiority, randomized control trial with a 1:1 allocation ratio.

According to previous studies neonatal $\mathrm{Hb}$ at 24 hours following DCC and UCM were $17.4 \mathrm{~g} / \mathrm{dl}$ and $18.6 \mathrm{~g} / \mathrm{dl}$ (sd 1.5) respectively ${ }^{20}$. Therefore to detect an increase of $\mathrm{Hb}$ of $1.2 \mathrm{~g} / \mathrm{dl}$ with $80 \%$ power at a $5 \%$ significant level the minimum sample size was calculated to be 23 per each $\mathrm{arm}^{23}$. Anticipating a drop out rate of $20 \%$ due to the inability of obtaining blood from the newborns and technical errors the sample size was increased to 30 per each arm.

Random number allocation sequence was developed. Concealment was done by inserting the code into sealed opaque envelops. On the outside envelopes were sequentially numbered. Envelopes were opened only after anaesthesia. The mother, paediatric team carrying out the initial assessment and the laboratory technicians were blinded.

All pregnant mothers assigned for elective $\mathrm{CD}$ at term from $1^{\text {st }}$ of February to $31^{\text {st }}$ March 2015 in Teaching Hospital Kandy (THK) were assessed for eligibility for recruitment. Multiple pregnancies, $\mathrm{Rh}$ negative mothers, maternal diabetes, oligohydramnios and estimated fetal weight below $2.5 \mathrm{~kg}$ and above $3.5 \mathrm{~kg}$ were excluded from the study. Selected mothers were given the consent forms and explained about the study by the principal investigator. Preoperative $\mathrm{Hb}$ of the participants were checked by drawing venous blood and the dating was rechecked going through the dating scans.

All the subjects underwent the CD under spinal anaesthesia at the Operating Theatre $\mathrm{C}$ of THK. The operating team was briefed on the research and three surgeons who were trained on the two methods of umbilical cord clamping carried out all the surgical procedures. Following delivery of the fetus all subjects were given intravenous oxytocin 5IU slowly according to the guidance on AMTSL. The DCC group at this point had the umbilical cord clamped after 2 minutes or once the cord pulsations had ceased which ever was earlier. The baby was covered with a sterile, dry and warm cloth to prevent hypothermia, and placed on the mother's thighs, until the cord was clamped and divided, in the DCC group. The UCM group had the umbilical cord milked towards the umbilicus of the baby three times with a $10 \mathrm{~cm} / \mathrm{s}$ speed per stroke followed by clamping of the cord $3 \mathrm{~cm}$ from the umbilicus. Rest of the surgery was carried out in the routine manner with two-layer closure of the uterus and meticulous achieving of haemostasis. Peritoneal defects were not sutured.

Routine postoperative monitoring was carried out after the CD. All subjects had an intravenous infusion of $500 \mathrm{ml}$ of normal saline over six hours followed by early establishment of oral feeds. All the mothers were discharged within three to four days of delivery and were informed of the blood investigation results of themselves as well as their newborns. They were offered the routine follow up at six weeks at THK.

Primary outcome of the study was the neonatal $\mathrm{Hb}$ and $\mathrm{HCT}$ within 24 to 48 hour of delivery. Neonatal APGAR and heart rate at 5 minutes, neonatal total serum bilirubin values within 24 to 48 hours after delivery and maternal blood loss were considered the secondary outcomes.

The newborns were immediately taken to the radiant warmer and the attending midwife and the peadiatric house officer assessed APGAR scores and neonatal heart rate at 5 minutes. Venous blood samples were withdrawn from the newborns within 24 to 48 hours of delivery for assessment of venous $\mathrm{Hb}, \mathrm{HCT}$ and the serum total bilirubin levels. Venous blood samples for maternal postoperative $\mathrm{Hb}$ were withdrawn within 24 hours to 48 hours of the procedure and compared with preoperative values for assessment of blood loss. Additionally the volume of blood remaining in the placenta was measured by keeping the placenta on a funnel with a measuring beaker attached to it. Venous $\mathrm{Hb}$ and HCT were assessed by the automated analyzer Sysmex, XN 1000 (Japan) and the serum bilirubin levels were assessed by the automated analyzer Beckman Coulter, AU 480 
(Japan). Analyzers were quality controlled and calibrated daily.

\section{Figure 1 - Flow Chart of the Trial}

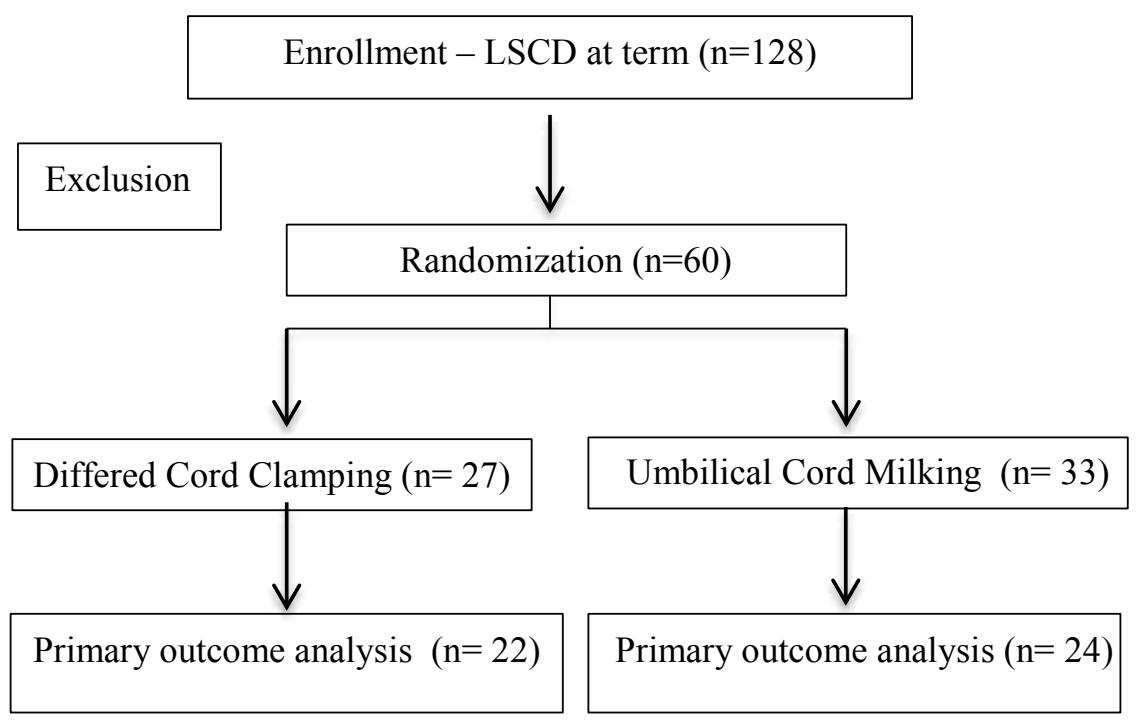

Results of the two groups were compared using independent sample $t$ test for comparison of means and chi-squared test for comparison of proportions.

\section{RESULTS}

Hundred and twenty-eight pregnant mothers undergoing elective $\mathrm{CD}$ were assessed for eligibility. Sixty subjects who fulfilled the inclusion criteria and gave consent were recruited for the study. Out of them $27(45 \%)$ subjects underwent DCC while $33(55 \%)$ subjects underwent UCM.

Due to blood collection errors and mothers leaving the trial not giving consent for neonatal blood drawing only 47 samples were available for analysis of the primary outcome. This consisted of 22 (48\%) from the DCC group and 24 (52\%) from the UCM group. (Figure 1)

There was no significant difference in characteristics of the participants between the two groups (Table 1)

There were no significant differences between the UCM and DCC groups with regard to mean neonatal Haemoglobin $(17.6 \mathrm{~g} / \mathrm{dl}$, sd 2.0 vs $17.4 \mathrm{~g} / \mathrm{dl}$, sd 2.4 , $\mathrm{p}=0.67)$, mean neonatal haematocrit $(54.5 \%$, sd 7.5 vs $54.9 \%$, sd 8.5 ,

Table 1 - Characteristics of the participants, their baseline interventions and birth outcomes

\begin{tabular}{|c|c|c|c|}
\hline \multirow[t]{2}{*}{ Characteristics } & \multicolumn{3}{|l|}{ Group } \\
\hline & $\begin{array}{l}\text { Cord Milking } \\
(\mathrm{n}=33)\end{array}$ & $\begin{array}{l}\text { Differed Cord clamping } \\
(\mathrm{n}=27)\end{array}$ & $P$ value \\
\hline Maternal age in years: mean (sd) & $31.1(4.6)$ & $29.3(6.6)$ & 0.21 \\
\hline $\begin{array}{l}\text { Maternal pre-pregnancy weight in } \mathrm{kg} \text { : } \\
\text { mean (sd) }\end{array}$ & $51.4(8.1)$ & $50.5(7.6)$ & 0.66 \\
\hline Maternal $\mathrm{Hb}$ in $\mathrm{g} / \mathrm{dl}$ : mean (sd) & $12.0(1.1)$ & $12.1(1.2)$ & 0.84 \\
\hline Use of oxytocin (\%) & 100 & 100 & - \\
\hline Antenatal iron supplementation (\%) & 100 & 100 & - \\
\hline $\begin{array}{l}\text { Antenatal folic acid supplementation } \\
(\%)\end{array}$ & 100 & 100 & - \\
\hline Medical conditions $(\%)$ & 15.2 & 11.1 & 0.72 \\
\hline Birth weight in g: mean (sd) & $2989(295.4)$ & $2869(233.4)$ & 0.09 \\
\hline Placental weight in g: mean (sd) & $589(101.8)$ & $543(105.6)$ & 0.10 \\
\hline Male gender neonate (\%) & 51.5 & 44.4 & 0.57 \\
\hline
\end{tabular}


Figure 2 - Distribution of neonatal haemoglobin values 24-48 hours after delivery (n=33 UCM, n=27 DCC)

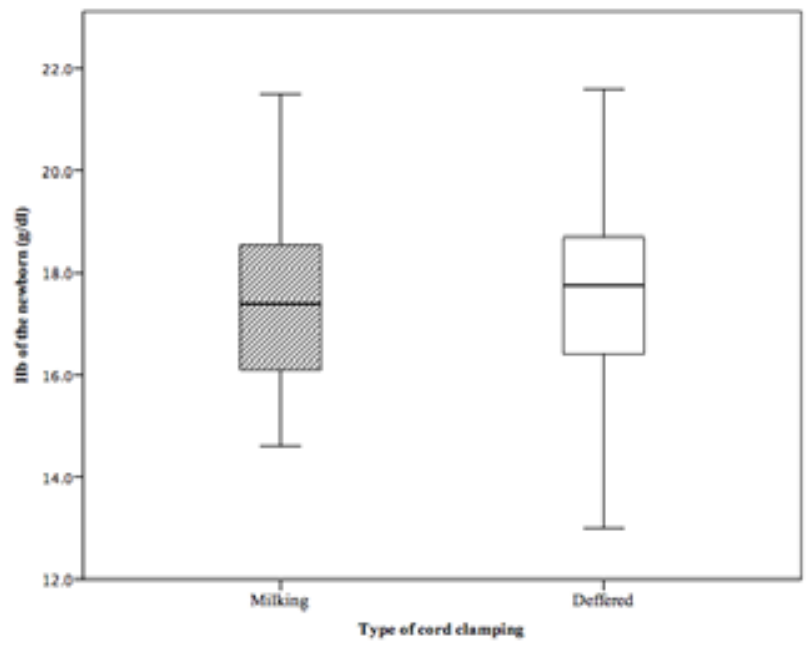

Figure 3 Distribution of neonatal haematocrit values 24-48 hours after delivery (n=33 UCM, n=27 DCC)

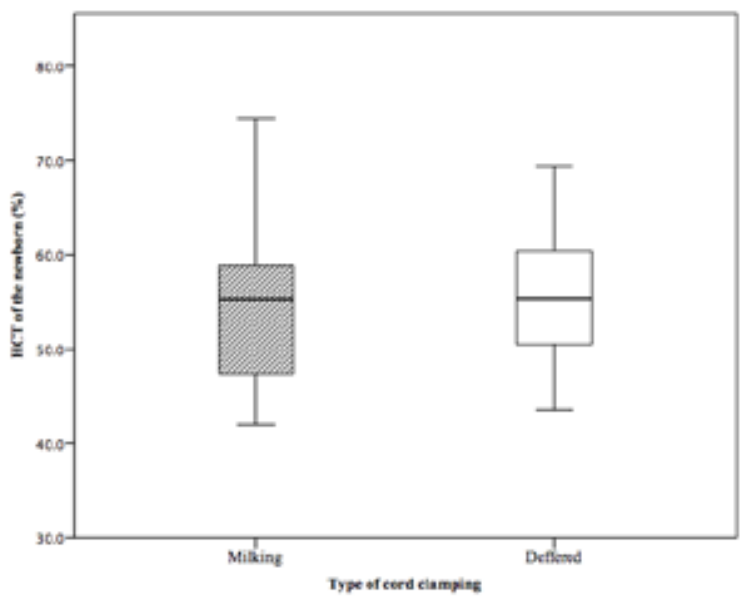

Figure 4 - Distribution of neonatal serum total bilirubin values, 24 - 48 hours after delivery $(\mathrm{n}=33 \mathrm{UCM}, \mathrm{n}=27$ DCC $)$

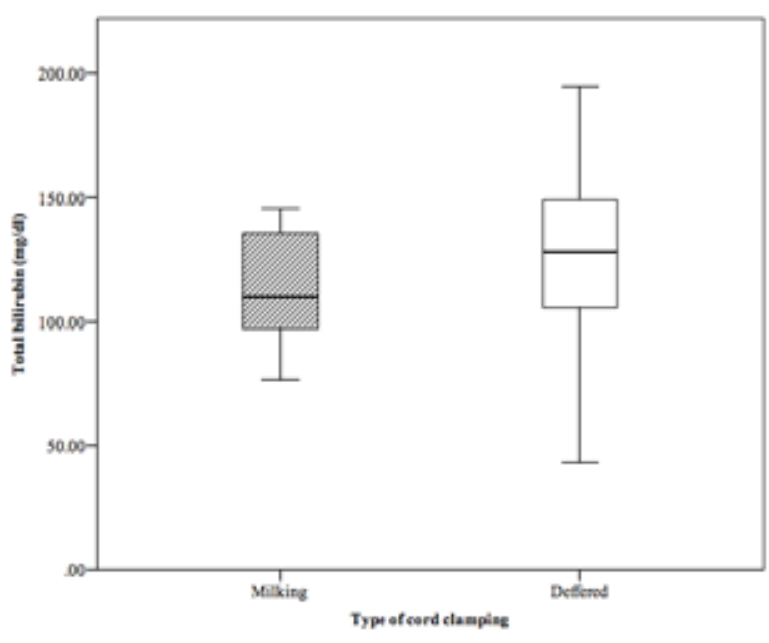

$\mathrm{p}=0.87)$, mean neonatal total bilirubin (111.8mmol/1, sd -47.6 vs $123.0 \mathrm{mmol} / 1$, $\mathrm{sd}$ - 35.0, $\mathrm{p}=0.69)$ and mean maternal decrease in $\mathrm{Hb}(1.0 \mathrm{~g} / \mathrm{dl}$, sd 0.7 vs $1.3 \mathrm{~g} / \mathrm{dl}$, sd 1.0, $\mathrm{p}=0.37)$. All the neonates had birth APGAR of 10 at 5 minutes. (Table 2).

However there was a statistically significant increased volume of blood remaining in the placenta in the UCM group $(29.5 \mathrm{ml}$, sd $20.3 \mathrm{vs} 19.5 \mathrm{ml}$, sd 13.1 , $\mathrm{p}=0.03$ ) and a statistically not significant trend towards a reduction of neonatal heart rate in the UCM group. (128bpm, sd 15.5 vs $119 \mathrm{bpm}$, sd 5.3, $\mathrm{p}=0.06$ ) (Table 2)

Figures 2-4 show distribution of neonatal $\mathrm{Hb}, \mathrm{HCT}$ and serum total bilirubin values 24-48 hours after delivery

\section{DISCUSSION}

Our results could not show that UCM was better than DCC with regard to increment in neonatal $\mathrm{Hb}$ and HCT. Although UCM did not result in any adverse perinatal outcomes as measured by neonatal serum bilirubin levels and APGAR scores, the study was not powered to detect these adverse effects.

There were several studies comparing UCM with DCC in preterm infants. But we could not find similar studies in term infants in the documented literature. Study by Rabe et al was similar to ours except that it was conducted in preterm neonates ${ }^{22}$. The results were comparable to our outcomes with neonatal HB values being $17.5 \mathrm{~g} / \mathrm{dl}$ for $\mathrm{UCM}$ and $17.3 \mathrm{~g} / \mathrm{dl}$ DCC group.

The increment in $\mathrm{Hb}$ did not reach a statistically significant level. This may be due to our study sample not being large enough to elicit this difference. Also we noted that significantly higher amount of blood was left in the placenta in the UCM group compared to DCC group. If this amount could be forced to the fetus it might have increased the $\mathrm{Hb}$ in the newborns of UCM arm further. Previous studies conducted had different number of sweeps (ranging from two to four) used for $\mathrm{UCM}^{9,22,24}$. Our method consisted of only three sweeps of the cord. Therefore if the number of sweeps were increased to four the effect may be higher reaching statistical significance.

Katheria at el studied haemodynamic changes in preterm infants following immediate cord clamping compared to $\mathrm{UCM}^{25}$. Although No difference was 
Table 2 - Outcomes

\begin{tabular}{|c|c|c|c|}
\hline \multirow[t]{2}{*}{ Outcome } & \multicolumn{3}{|l|}{ Group } \\
\hline & Cord milking $(\mathrm{n}=33)$ & $\begin{array}{l}\text { Differed cord clamping } \\
(\mathrm{n}=27)\end{array}$ & $\mathrm{p}$ Value \\
\hline $\mathrm{Hb}$ of the newborn in $\mathrm{g} / \mathrm{dl}$ : mean $(95 \% \mathrm{CI})$ & $17.6(16.8-18.5)$ & $17.4(16.3-18.5)$ & 0.67 \\
\hline HCT of the newborn (\%): mean $(95 \% \mathrm{CI})$ & $54.5(51.2-57.8)$ & $54.9(50.9-58.9)$ & 0.87 \\
\hline APGAR of 10 at 5 minutes $(\%)$ & 100 & 100 & - \\
\hline $\begin{array}{l}\text { Neonatal heart rate at } 5 \text { minutes of birth in beats per } \\
\text { minute: mean }(95 \% \mathrm{CI})\end{array}$ & $119(117-123)$ & $128(118-140)$ & 0.06 \\
\hline $\begin{array}{l}\text { Total bilirubin of the newborn in mmol/l: mean }(95 \% \\
\text { CI) }\end{array}$ & $111.8(88.9-134.7)$ & $123.0(106.7-139.4)$ & 0.67 \\
\hline Maternal $\mathrm{Hb}$ decrease in $\mathrm{g} / \mathrm{dl}$ : mean $(95 \% \mathrm{CI})$ & $1.0(0.7-1.4)$ & $1.3(0.9-1.7)$ & 0.37 \\
\hline Blood left in placenta in ml: mean $(95 \% \mathrm{CI})$ & $29.5(22.0-36.9)$ & $19.5(14.2-24.7)$ & 0.03 \\
\hline
\end{tabular}

found in heart rate and blood pressure they found an increase in superior vena cava blood flows and systemic blood flows. $10 \%$ (119 bpm in UCM vs $128 \mathrm{bpm}$ in DCC) this is probably of no clinical significance. However if the number of sweeps were increased to further increase $\mathrm{Hb}$ levels in neonate, this may lead to a further drop in FHR making the effect clinically significant.

Cochrane review by McDonald at el showed that there is no significant difference in the risk of moderate to severe post partum haemorrhage by the timing of cord clamping (RR - 1.04, 95\%CI 0.65 $1.65)^{6}$. In our study the haemoglobin drop was $1.3 \mathrm{~g} / \mathrm{dl}$ for the DCC group and $1.0 \mathrm{~g} /$ $\mathrm{dl}$ for the UCM group. The $\mathrm{Hb}$ drops in our study were higher in comparison to the meta-analysis findings. This difference may be explained by the fact that the entire subject underwent $\mathrm{CD}$ with a higher blood loss compared to most undergoing vaginal deliveries in the Cochrane review.

\section{STRENGTHS AND LIMITATIONS}

The main strength of our study was the meticulous way of cord milking, which was standardized and was carried out only by three surgeons who were trained on the exact method.

Primary end point of the study was neonatal $\mathrm{Hb}$. There were difficulties associated with blood collection, which led to dropouts from the study. The difficulties encountered were the mothers changing their minds and not giving consent for blood collection of their newborns following $\mathrm{CD}$, collection errors such as unable to get an adequate sample as well as clotting of the samples during transport. Since we further inflated our sample by $20 \%$ expecting these dropouts we were able to overcome this problem without compromising on the quality of the research. However the sample size was calculated to assess the primary end point. Therefore the study was not powered enough to assess for adverse perinatal outcomes.

We did not measure the circulating blood volumes in neonates. Blood volume assessment can be done with either biotin labeling or red cells method, which is time consuming, expensive and difficult to perform on a large number of neonates or diluting adult hemoglobin in fetal blood and comparing this with circulating fetal hemoglobin, which is limited to neonates who require a donor blood transfusion ${ }^{(23,}$ ${ }^{25)}$. Due to these limitations we adhered to measurements in venous $\mathrm{Hb}$ and $\mathrm{HCT}$.

\section{CONCLUSIONS AND RECOMMENDATIONS}

UCM was not better than DCC in increasing neonatal $\mathrm{Hb}$ within 24 hours of birth following elective CD. However there is no additional risk of neonatal jaundice, worsening fetal haemodynamic parameter or APGAR scores with UCM.

Since the UCM group had significantly higher amount of blood left in the placenta increasing the number of sweeps during milking could further increase the $\mathrm{Hb}$ levels in neonates which needs further studies. A trend towards a decrease of FHR in UCM group needs to be further evaluated with an adequately powered sample to detect these subtle adverse perinatal outcomes.

\section{ACKNOWLEDGEMENTS}

We would like to thank Dr.Lakshman Kariyawasam and Dr. Sardha Hemapriya for their efforts and assistance that contributed to this study and Prof. Malik Goonawardena for editing the manuscript. Finally, we wish to thank all of the women who participated in this study

\section{DETAILS OF ETHICS APPROVAL}

Ethical approval for the study was taken from the Ethical Review committee of THK.

\section{AUTHOR CONTRIBUTIONS}

PI, DAD, GK designed the study. PI and DLC contributed to the data collection. PI and DLC performed the data analysis. PI and DAD prepared the article for submission. PI, DAD and GK revised it critically for important intellectual content. All authors approved the final version.

\section{REFERENCES}

1. Sri Lanka Demographic and Health Survey (DHS) 2006-7. Colombo; 2009.

2. Stoltzfus RJ, Mullany L, Black RE. Iron deficiency anaemia. In: Comparative quantification of health risks. p. 163. available at http://www. 
who.int/publications/cra/chapters/ volume1/0163-0210.pdf. (Accessed 21 June 2014)

3. Yao A. Distribution of blood between infant and placenta after birth. Lancet 1969; 294(7626): $871-873$.

4. Usher R, Shephardz M, Lind J. The Blood Volume of the Newborn Infant and Placental Transfusion. Acta Paediatrica 1963; 52(5): 497 - 512.

5. Andersson $\mathrm{O}$, Andersson D, Domellöf M. Effect of delayed versus early umbilical cord clamping on neonatal outcomes and iron status at 4 months : a randomised controlled trial. British Medical Journal 2011; 7157(November): 1 - 12.

6. McDonald SJ, Middleton P. Effect of timing of umbilical cord clamping of term infants on maternal and neonatal outcomes. Cochrane Database of Systematic Reviews 2008, Issue 2. Art. No.: CD004074. DOI: 10.1002/14651858.CD004074.pub2.

7. Rheenen P, Moor L, Eschbach S, Grooth H, Brabin B. Delayed cord clamping and haemoglobin levels in infancy: a randomised controlled trial in term babies. Tropical Medicine and International Health 2007; 12(5): $603-616$.

8. McDonnell M, Henderson-Smart DJ. Delayed umbilical cord clamping in preterm infants: a feasibility study. J Paediatr Child Health 1997;33:30810.

9. Hosono S, Mugishima H, Fujita H, Hosono a, Okada T, Takahashi S, Masaoka M, Yamamoto T. Blood pressure and urine output during the first $120 \mathrm{~h}$ of life in infants born at less than 29 weeks' gestation related to umbilical cord milking. Arch Dis Child Fetal Neonatal Ed 2009; 94(5): $328-331$.
10. Yao AC, Lind J, Vuorenkoski V. Expiratory grunting in the late clamped normal neonate. Pediatrics 1971;48:865-70.

11. Saigal S, Usher RH. Symptomatic neonatal plethora. Biol Neonate 1977;32:62-72.

12. Werner EJ. Neonatal polycythemia and hyperviscosity. Clin Peri- natol 1995;22:693-710.

13. Blackburn S, Loper D. Maternal, fetal, and neonatal physiology. Philadelphia: W B Saunders, 1992. 11. Polin R, Fox W. Fetal and neonatal physiology, 2nd ed. Philadelphia: W B Saunders, 1998.

14. Harding JE, Elbourne DR, Prendiville WJ. Views of mothers and midwives participating in the Bristol randomized, controlled trial of active management of the third stage of labor. Birth 1989;16:1-6.

15. World Health Organization. WHO Recommendations for the Prevention of Postpartum Haemorrhage. Geneva: World Health Organization, 2006.

16. NICE. Intrapartum care for healthy women and babies. NICE 2014.

17. Inch S. Management of the third stage of labour: another cascade of intervention? Midwifery 1985;1:114-22

18. Wang Y Zhao S. Placental blood circulation. In: Vascular biology of the placenta. Morgan and Claypool Life Sciences, San Rafael (CA). 2010. Available on https://www. ncbi.nlm.nih.gov/books/NBK53254/. (Accessed 17 February 2017)

19. Davies L, McDonald S. Examination of the Newborn \& Neonatal Health: A Multidimensional Approach. British Journal of Midwifery 2009; 17(2): $116-117$.
20. Colozzi A. Clamping of the umbilical cord, its effects on the placental transfusion. New England Journal of Medicine 2010; 250(15): 629 - 630.

21. Erickson DA, Mercer JS, Oh W. Umbilical cord milking in term infants delivered by cesarean section: a randomized controlled trial. Journal of Perinatology 2012; 32(8): $580-$ 584.

22. Rabe H, Jewison A, Alvarez RF, Crook D, Stilton D, Bradley R. Milking compared with delayed cord clamping to increase placental transfusion in preterm neonates: a randomized controlled trial. Obstetrics Gynecology 2011; 117 (2): 205-11.

23. Rollin Brant: Inference for Means: Comparing Two Independent Samples. Available from: https://www.stat.ubc.ca/ rollin/stats/ ssize/n2.html [Accessed 14th June 2014]

24. Upadhyay A, Gothwal S, Parihar R, Garg A, Gupta A, Chawla D, Gulati IK. Effect of umbilical cord milking in term and near term infants: randomized control trial. American Journal of Obstetrics and Gynecology 2013; 208(2): 120.e1 - 120.e6.

25. Katheria AC, Leone TA, Woelkers D, Garey DM, Rich W, Finer NN. The effects of umbilical cord milking on hemodynamics and neonatal outcomes in premature neonates. The Journal of Pediatrics 2014; 164(5): $1045-1050$. 